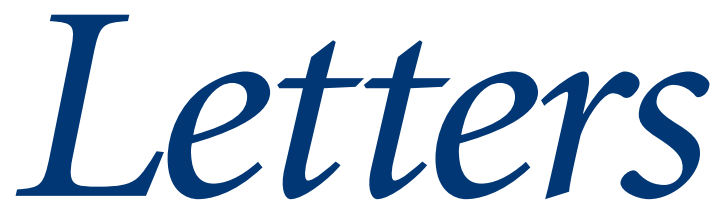

All letters are subject to editing and may be shortened. Letters should be sent to the BJGP office by e-mail in the first instance, addressed to

journal@rcgp.org.uk (please include your postal address). Alternatively, they may be sent by post as an MS Word or plain text version on CD or DVD. We regret that we cannot notify authors regarding publication. Letters not published in the Journal may be posted online on our Discussion Forum. For instructions please visit: http://www.rcgp.org.uk/bjgp-discuss

\section{Quality of life measures}

The editorial on 'Quality of life: what does it mean for general practice?'1 suggests that including patient-reported quality of life in chronic disease management may help health professionals to understand more about the patient's perspective. In relation to the important question of how best to measure changes in quality of life for patients who have more than one chronic condition, Jacobs suggests using a generic questionnaire such as the EQ$5 \mathrm{D}$, despite its limited sensitivity to change and lack of attention to the details of any particular health problem.

An alternative, and one suited particularly to the provision of integrated holistic care, is to use an individualised outcome questionnaire. There are a number to choose from: Measure Yourself Medical Outcome Profile ${ }^{2}$ is a brief questionnaire developed specifically for use in multidisciplinary general practice that asks the patient to nominate the health problem that is most important to them on the day of attendance, and then score its severity across several dimensions. Consequently, it informs clinicians about patients' priorities and individual perceptions and is applicable across many health conditions (http://sites.pcmd.ac.uk/mymop/).

A more generic measure of individualised health-related quality-of-life is provided by the Patient-Generated Index ${ }^{3}$ which, while it is more complex to administer, has been validated in a wide range of patient populations. Taking an even broader view of quality-of-life, within which health is only one of many possible dimensions, is the Schedule for the Evaluation of Individual Quality of Life, ${ }^{4}$ which highlights social and environmental influences on health. Individualised outcome questionnaires have the potential to promote shared understanding and decision making, as well as truly patient-centred outcome measurement.

\section{Charlotte Paterson,}

Senior Research Fellow, Institute of Health

Service Research, Peninsula Medical School, University of Exeter, EX1 2LU.

E-mail: charlotte.paterson@pms.ac.uk

\section{REFERENCES}

1. Jacobs JE. Quality of life: what does it mean for general practice? Br J Gen Pract 2009; 59(568): 807-808.

2. Paterson C. Measuring outcomes in primary care: a patient generated measure, MYMOP, compared with the SF-36 health survey. BMJ 1996; 312(7037): 1016-1020.

3. Ruta DA, Garratt AM, Leng M, et al. A new approach to the measurement of quality-of-life. The PatientGenerated Index. Med Care 1994; 32(11): 1109-1026.

4. Hickey A, Bury G, O'Boyle CA, et al. A new short form individual quality of life measure (SEIQoLDW): application in a cohort of individuals with HIV/AIDS. BMJ 1996; 313(7048): 29-33.

DOI: 10.3399/bjgp10X482121

\section{Antidepressant prescribing for older adults}

The recent paper by Cameron et al/ raises some underlying issues regarding antidepressant prescribing for older adults.

The study indicated that 'all adult patients' were eligible to participate. However, the mean age was 48 years (SD = 18 years). This suggests that almost no participants were over the age of 65 years. The study also stated 'detected participants tended to be younger'.

Our concerns are twofold. Firstly, the paper is misleading if there was an upperage cut off in this study, or older people were excluded without that being stated. Secondly, if older people were included, then why was their depression not detected? Was there an assumption that depressive symptoms are an inevitable part of old age and, therefore, depression was not considered an appropriate clinical diagnosis, which would ultimately lead to undertreatment? ${ }^{2}$

The study debunks the view that GPs are to blame for an increase in antidepressant prescribing, but does not answer the question of the real cause for this increase. A timely paper by Moore et $a / 3$ illuminates this issue. This primary care study confirms an increase in the number of overall prescriptions $(2.8 \%$ in 1993 to $5.6 \%$ in 2004), but suggest this is due to patients being prescribed antidepressants for a longer duration with an increase in repeat prescriptions. Older people, with a higher tendency to experience relapses of depression, would be likely to benefit from longer-term prescribing. ${ }^{4}$

The paper also did not mention rates of benzodiazepine prescribing. One hopes that benzodiazepine prescriptions are inversely related to antidepressant prescribing for depression. Higher rates of antidepressant prescribing are likely to be preferable to alternative drug regimes. Again, this has specific relevance to older people who may be particularly sensitive to side effects of benzodiazepines.

All in all, we think these issues should be addressed, especially the lack of identification of depression in older people in this study. This is of concern because depression in old age is as common as in younger people, and is associated with equal if not higher rates of suicide. 


\section{Aman Bahri,}

Service for Older People, CNWL NHS

Foundation Trust, Bentley House,

15-21 Headstone Drive, HA3 5QX.

E-mail: amanbahri@hotmail.co.uk

\section{Claire Hilton,}

Consultant Old Age Psychiatrist, CNWL NHS

Foundation Trust, Northwick Park Hospital.

\section{REFERENCES}

1. Cameron IM, Lawton K, Reid IC. Appropriateness of antidepressant prescribing: an observational study in a Scottish primary-care setting. Br J Gen Pract 2009; 59(566): 644-649.

2. Department of Health. National Service framework for older people. London: Department of Health, 2001. http://www.dh.gov.uk/dr_consum_dh/groups/dh_dig italassets/@dh/@en/documents/digitalasset/dh_40712 83.pdf (accessed 4 Dec 2009)

3. Moore M, Yuen HM, Dunn N, et al. Explaining the rise in antidepressant prescribing: a descriptive study using the general practice research database. $B M J$ 2009; 339: b3999.

4. National Collaborating Centre for Mental Health. Depression in adults (update). Depression: the treatment and management of depression in adults. London: National Institute for Health and Clinical Excellence, 2009.

http://www.nice.org.uk/nicemedia/pdf/Depression_U pdate_FULL_GUIDELINE.pdf (accessed 4 Dec 2009)

DOI: 10.3399/bjgp10X482130

\section{RCGP autumn conference}

At the close of the Royal College of General Practitioners' Annual National Primary Care Conference (Glasgow 5-7 November), the College Treasurer remarked that he had received many warm congratulations on the success of the conference, and not one adverse comment. That is not a healthy state of affairs. I am very happy to fill in online the College's evaluation questionnaire and give credit to an extremely well organised, smoothly run, professional, and indeed very enjoyable conference. We all no doubt have our favourite moments; I thought Dr Harry Burns on health inequalities was outstanding, and the highlight of the conference was the presentation on Maori health from a group based in Kaitaia, Northland, New Zealand.

However, I didn't learn any Medicine. I was very struck by the scarcity of clinical material throughout: in the plenary sessions, the concurrent streams, the fringe meetings, even, though to a lesser extent, in the poster presentations. We are obsessed with Process.

As an exercise, I have gone through the conference programme, allocating each session to one of two groups: either 'clinical' or 'non-clinical' depending both on the subject matter, and whether the speaker or panel were addressing issues of practical clinical medicine, or broader issues of policy, management, governance, process, philosophy, and so forth.

Of a total of 104 sessions, I assigned $20(19 \%)$ to the 'clinical' category, and 84 $(81 \%)$ to the 'non-clinical' category. I looked at the split as it occurred in the three types of session on offer: plenary, concurrent stream, and fringe. There were two clinical and 17 non-clinical plenary sessions ( $11 \%$ versus $89 \%$ ), 10 clinical and 46 non-clinical sessions in the concurrent streams (18\% versus $82 \%$ ), and eight clinical and 21 non-clinical fringe meetings (28\% versus $72 \%$ ). I counted a total of 132 poster presentations: 38 of these were clinical, and 94 non-clinical (29\% versus $71 \%$ ).

I would stress that I am not arguing that a clinical presentation is 'better' than a non-clinical one, nor indeed that a nonclinical presentation could not radically change the way we work; it is merely a matter of ratio and proportion: we needed more medicine.

\section{Hamish Maclaren,}

Aberfoyle Medical Practice, Main Street, Aberfoyle, Stirlingshire, FK8 3UX. E-mail: hamish.maclaren@virgin.net

DOI: 10.3399/bjgp10X482149

\section{RCGP Fellowship}

I have recently been elected a Fellow of the College, which I consider to be both a great honour and a great achievement. I had put myself forward to be considered via the Unified Route to Fellowship (http://www.rcgp.org.uk/ membership/fellowship.aspx) and I would urge all experienced and established Members to consider doing the same themselves.

It is easy to feel overshadowed by those who stand out in some particular way (who may well also put themselves forward for consideration, of course): but I know that I am not the star striker, or the demon bowler, nor the Olympic gold medal winner. No, I am a solid, dependable, all-rounder in the first team (which in my case includes everyone who works with me in the practice of which I am a partner).

The standard required for Fellowship is appropriately high, the process to be followed is rigorous, as it should be. Yet, I think that it is achievable by any Member who is committed, hardworking, aspiring to, and attaining high standards in clinical practice, or one or more other areas of general practice or primary care work. For me it involved describing what I already actually do in practice, and organising data, and other material I already had; in other words, it was not a large burden.

I think that the Unified Route to Fellowship is a good way for many colleagues like me now to receive the recognition they too deserve of their stature in the profession.

Mick Leach, GP, Harrogate. E-mail: Mick.Leach@gp-b82013.nhs.uk

DOI: 10.3399/bjgp10X482158

\section{Correction}

In the editorial: Pollock AM, Richardson L. Commercial confidentiality: a cloak for policy failure. Br J Gen Pract 2009; 59(569): 893-894, the text reads:

'At the time of writing, the NHS Choices website stated that the Department of Health is: “... taking [the seven centres] over from the independent sector ...".'

Following publication, the Department of Health has retracted this statement, as it is not planning on taking over these centres from the private sector, and will correct this information on their website.

DOI: 10.3399/bjgp09X473385 